\title{
STUDY ON CONVERSION OF VEGETABLE OIL DEODORIZER DISTILLATE TO BIODIESEL USING MESOPOROUS OXO- PHOSPHATED SULFATED ZIRCONIA
}

\author{
Phong Van Pham ${ }^{1}$, Hong Khanh Dieu Nguyen ${ }^{2, *}$ \\ ${ }^{I}$ Vietnam National Oil and Gas Group, 18 Lang Ha Street, Ba Dinh, Hanoi \\ ${ }^{2}$ Hanoi University of Science and Technology, 1 Dai Co Viet Street, Hai Ba Trung, Hanoi \\ *Email: dieuhong_bk@yahoo.com
}

Received: 11 April 2016; Accepted for publication: 15 September 2016

Mesoporous oxo - phosphated sulfated zirconia (m-PSZ) were applied for converting vegetable oil deodorizer distillate to biodiesel in one-step reaction. The catalyst possessed mesopores, high surface area and strong acid sites while the feedstock contained mainly free fatty acids. Many investigations were established for finding the most suitable conditions of the biodiesel synthesis process.

Keywords: mesoporous, zirconia, oxo-phosphate, deodorizer distillate.

\section{INTRODUCTION}

Biodiesel was an environmentally friendly fuel as it was made from renewable resources and $\mathrm{CO}_{2}$ balance. It was derived from the esterification of free fatty acids or the transesterification of triglycerides with methanol or ethanol. The base catalyzed process suffered from some limitations of feedstock, ecspecially the acid value must be lower than 1 avoiding the saponification during the alcoholysis [1,2]. Therefore, in case of rich free fatty acid feedstocks, the solid acid catalysts were preferable [3]. Recently, there have developed various solid acids for the esterification of long chain fatty acids including sulfonated carbonized sugar [4], sulfated zirconia [5] and organosulfonic acid mesoporous silica [6]. However, the activities of most of these catalysts were still low in comparison with sulfuric acid. It was desirable to further develop good solid acid catalyst with high catalytic activity and stability for both esterification of fatty acids and transesterification of triglycerides. There were several considerations in the development of a strong solid acid for the purpose. First, the catalyst needed to be highly dispersed in order to bring out a large number of active acid sites. Second, mesoporosity in the catalyst would be able to accommodate the relatively larger molecules of fatty acid. Finally, the catalyst required to be water-tolerant since water is a byproduct of the esterification process.

Mesoporous sulfated zirconia ( $\mathrm{m}$-SZ) was also a kind of the metal oxide derived mesostructured material exhibiting its high surface area, superacid sites, and it was a good potential for widening applications of the traditional zirconia based acid materials. The major problem for synthesizing the $\mathrm{m}$-SZ material still belonged to its low thermal stability leading to collapse the mesopores during the template removal at high temperature. One of the best 
solution for improving the thermal stability of the $\mathrm{m}-\mathrm{SZ}$ material was to change its surface state through the oxophosphate process. In which, the oxophosphate groups could be used to lock the - $\mathrm{OH}$ groups attached on the zirconium sites; therefore the zirconium site could ensure its oxidation state during the calcination, and the catalyst could be assigned as m-PSZ catalyst. In a previous paper, both $\mathrm{m}-\mathrm{SZ}$ and $\mathrm{m}-\mathrm{PSZ}$ catalyst were synthesized through condensation method in alkaline solution followed by oxo-phosphated process [7].

Vegetable oil deodorizer distillate was one of the cheapest feedstock that could be used for biodiesel synthesis. The drawback of this feedstock was its very high acid value limiting its applications when using the traditional base catalysts because of the saponification. The problem could be solved by using a suitable solid acid. The m-PSZ catalyst exhibited superacid property, high surface area and good thermal stability which could play an important role in the conversion of free fatty acids and triglycerides in the deodorizer distillate to biodiesel in an onestep reaction.

\section{EXPERIMENTALS}

\subsection{Chemicals}

Zirconyl chloride $\left(\mathrm{ZrOCl}_{2} \cdot 8 \mathrm{H}_{2} \mathrm{O}\right)$, cetyltrimethylammonium bromide (CTAB), sulfuric acid $\left(\mathrm{H}_{2} \mathrm{SO}_{4}\right)$, ammonia solution were all purchased from Merck and used as received; deodorizer distillate collected from the Cailan Vegetable Refinery in Quang Ninh province, Vietnam was pretreated by heating up to $120{ }^{\circ} \mathrm{C}$ for 2 hour to complete water removal before used; distilled water was prepared in our own laboratory.

\subsection{Preparation of m-PSZ catalyst}

The m-PSZ catalyst was prepared in previous paper [7], in which the synthesized m-SZ material was sinked into $20 \mathrm{ml}$ solution of $\mathrm{H}_{3} \mathrm{PO}_{4} 1 \mathrm{M}$ in combination with well stirring. The mixture was maintained for 24 hours at ambient temperature; then the precipitate was filtered and dried at $110{ }^{\circ} \mathrm{C}$ overnight. This dried powder was then calcinated at $450{ }^{\circ} \mathrm{C}$ for 6 hours to obtain mesoporous oxophosphated sulfated zirconia (m-PSZ). Characterizations of the m-PSZ catalyst were also established in the paper [7] including powder XRD, TG-DTA, BET, TEM, $\mathrm{NH}_{3}$-TPD pointing out its mesoporous structure, strong acid sites and high surface area.

\subsection{Conversion of vegetable oil deodorizer distillate to biodiesel over the m-PSZ catalyst}

The deodorizer distillate feedstock with volume of $40 \mathrm{ml}$ was transferred to an autoclave reactor supported magnetic stirrer and heater. A precise mass of the m-PSZ catalyst was then carefully measured and homogeneously mixed with the feedstock before closing the reactor. The temperature was risen to a definited temperature and lasted for a suitable period of time. The stirring speed was also surveyed for maintaining the good mixing of all chemical components in order to completely convert the feedstock to methyl esters under auto-pressurized condition.

After the reaction completed a decantation was applied to separate upper liquid phase including biodiesel and excess methanol for further purification. The purification was performed by rinsing the liquid with hot water for a certain time followed by drying the raw biodiesel at $120{ }^{\circ} \mathrm{C}$ for 2 hours to obtain refined biodiesel. The biodiesel yield was calculated by the yield kinetic viscosity relation obtained from the paper [8]. The yield - kinetic viscosity equation was described as $\mathrm{Y}=-6.00 \mathrm{X}+129.20$ [8], in which $\mathrm{Y}$ was the biodiesel yield, and $\mathrm{X}$ was the kinetic viscosity of the refined biodiesel at $40{ }^{\circ} \mathrm{C}$. The chemical composition of the refined biodiesel at 
the highest yield was determined by GC-MS to estimate the catalyst activity, and some characteristics of the refined biodiesel were determined to illustrate the applicable of this process in the biodiesel synthesis.

\section{RESULTS AND DISCUSSION}

\subsection{Some properties of the m-PSZ catalyst}

A series of the m-PSZ catalysts properties were described in Table 1. These results were collected from our previous publications.

Table 1. The properties of the m-PSZ catalyst.

\begin{tabular}{|l|l|l|l|}
\hline No. & Properties & Methods & Values \\
\hline 1 & Bulk density & ASTM D 6683 & 0.3586 \\
\hline 2 & Surface area, $\mathrm{m}^{2} / \mathrm{g}$ & BET & 629.6 \\
\hline 3 & Concentrated pore diameter, $\AA$ & BJH & 38.06 \\
\hline 4 & Structure & XRD & Amorphous \\
\hline 5 & Superacid desorbed temperature, ${ }^{\circ} \mathrm{C}$ & $\mathrm{NH}_{3}$-TPD & 506.9 \\
\hline 6 & Superacid sites, $\mathrm{mmol}^{-\mathrm{g}}$ & $\mathrm{NH}_{3}$-TPD & 0.51 \\
\hline 7 & Thermal stability, $^{\circ} \mathrm{C}$ & TG-DTA $^{-}$ & $\sim 550$ \\
\hline
\end{tabular}

The m-PSZ catalyst existed in amorphous phase providing the ordered mesoporous structure with very high surface area of $629.6 \mathrm{~m}^{2} / \mathrm{g}$. The concentrated pore diameter belonged to the mesoporous group, and it was large enough for enhancing the diffusion of the free fatty acids and triglycerides in the deodorizer distillate to the strong acid active sites located on the catalysts surface. Beside the m-PSZ catalyst exhibited considerable thermal stability in comparison to the $\mathrm{m}$-SZ catalyst [7] leading to protect the meso-walls from the collapse during the calcination for template removal. The acidity of the m-PSZ catalyst observed from the Tab. 1 showed its very strong superacid sites with the desorbed temperature of $506.9{ }^{\circ} \mathrm{C}$ during $\mathrm{NH}_{3}$-TPD establishment, and the amount of superacid sites was very high. These properties clearly pointed out that the m-PSZ catalyst was a potential candidate to be applied in the biodiesel synthesis.

Some characterizations of the m-PSZ catalyst including XRD, BET and BJH were displayed in Fig. 1 and Fig. 2. The appearances of finger print peaks at positions of $2 \square=\sim 2^{\circ}$ and $\sim 4{ }^{\circ} \mathrm{C}$ in the small angle XRD pattern clearly confirmed the ordered mesoporous structure of the m-PSZ catalyst, and the absences of crystalline peaks in the wide angle XRD pattern also illustrated the amorphous existence of the catalyst as mentioned above.

The hysteresis appeared in relative pressure ranged from 0.4 to 0.9 because of the capilary condensation of the nitrogen vapor in the technique procedure. This phenomenon also demonstrated the mesoporous structure of the m-PSZ catalyst. The BJH analysis confirmed the concentrated pore diameter with a sharp and intensive peak at $\sim 38 \AA$. 


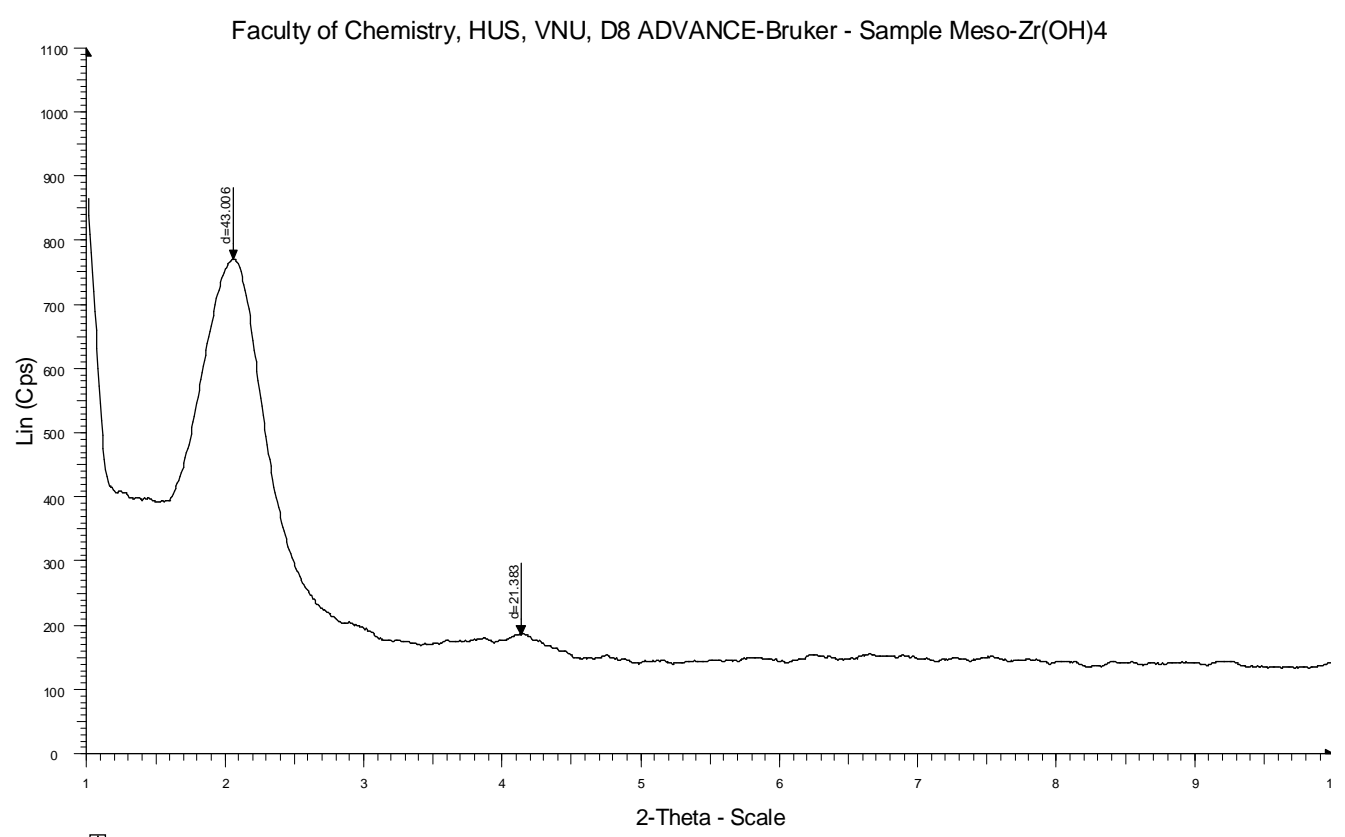

Wfilie: Toan BK mau Meso-Zr(OH)4.raw - Type: 2Th/Th locked - Start: $1.000^{\circ}$ - End: $10.000^{\circ}$ - Step: $0.008^{\circ}$ - Step time: $1 . \mathrm{s}$ - Temp. $25^{\circ} \mathrm{C}$ (Room) - Time Started: 8 s - 2-Theta: $1.000^{\circ}$ - Theta: $0.500^{\circ}$ - Chi:

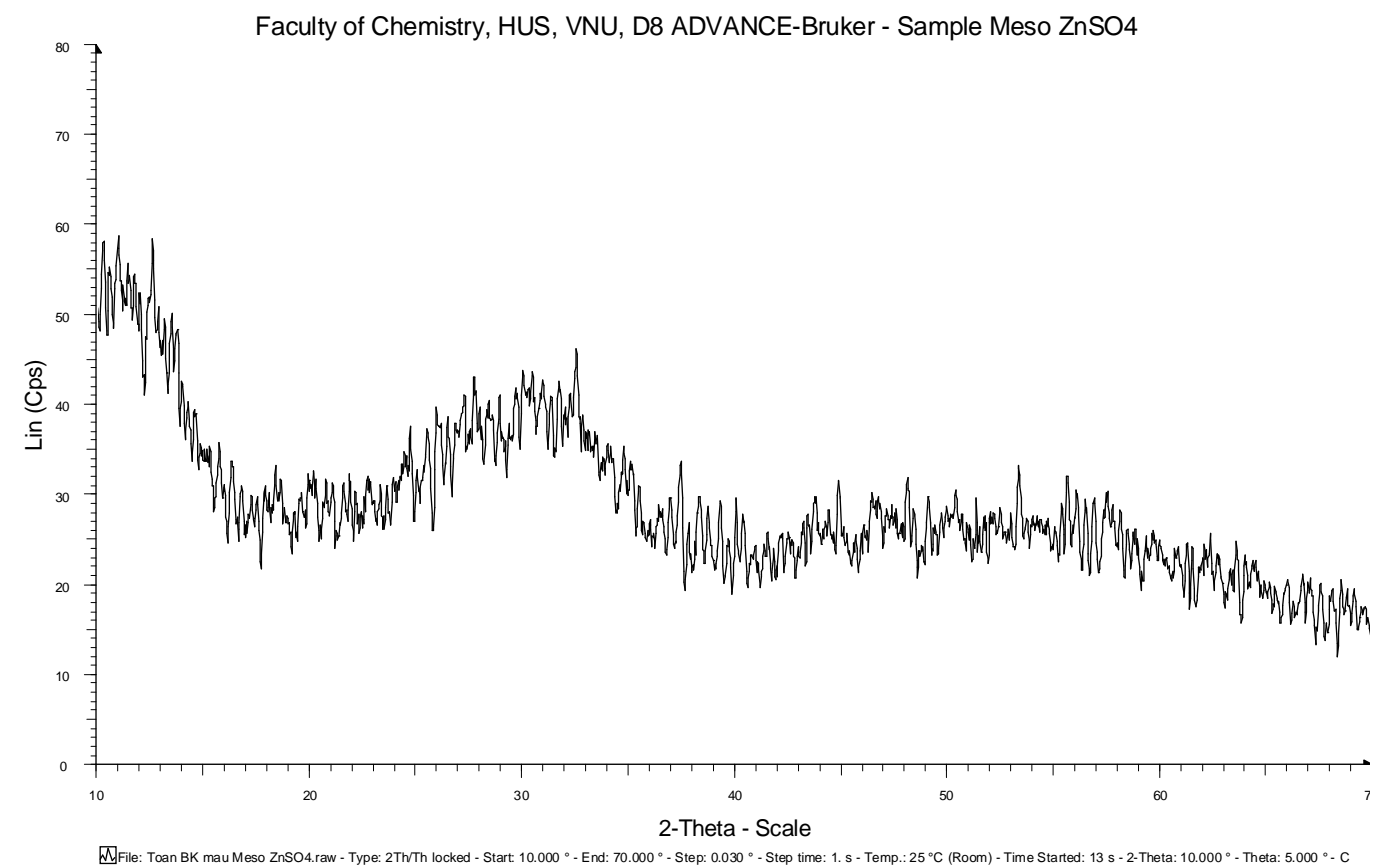

Figure 1. Small and wide angle powder XRD patterns of the m-PSZ catalyst. 


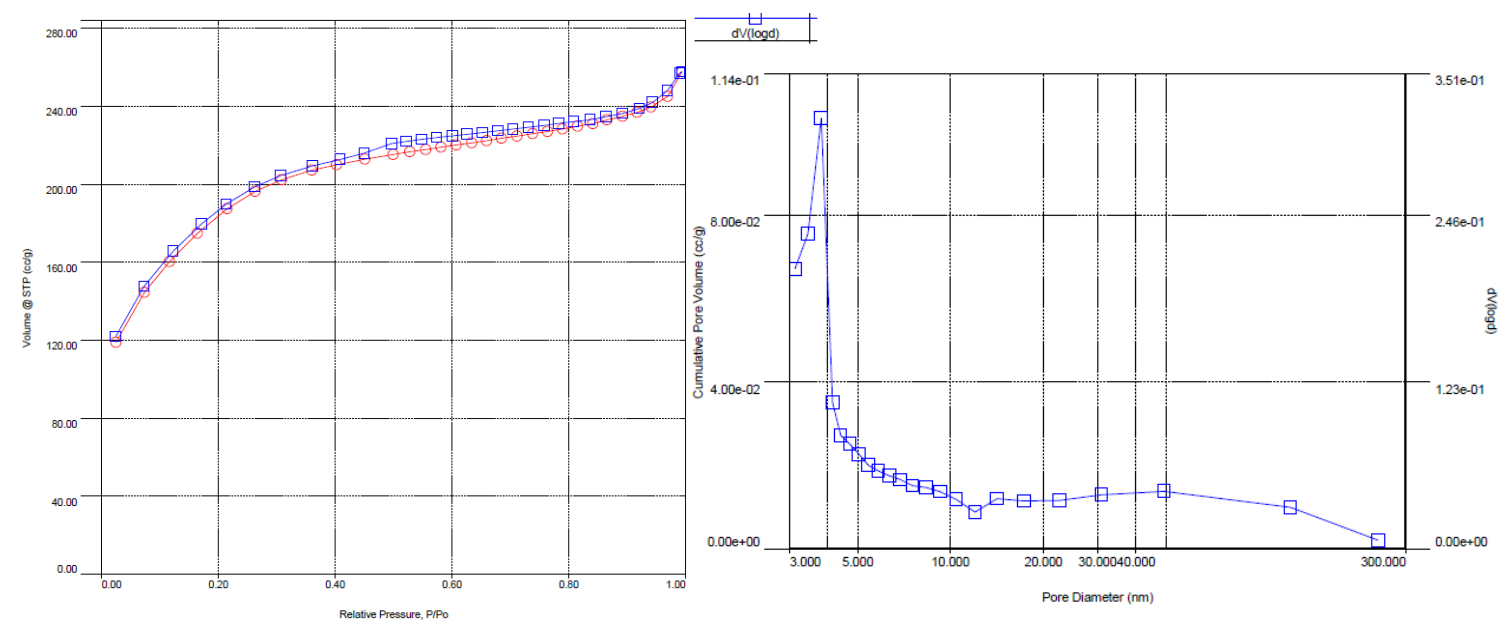

Figure 2. Adsorption - desorption isotherm and pore distribution diagram.

\subsection{Some properties of the vegetable oil deodorizer distillate}

Table 2 described some major properties of the vegetable oil deodorizer distillate. The properties were all determined by using ASTM and EU standards.

Table 2. The specifications of the vegetable oil deodorizer distillate.

\begin{tabular}{|l|l|l|l|}
\hline No. & Properties & Methods & Values \\
\hline 1 & Density at $25{ }^{\circ} \mathrm{C}$ & $\mathrm{D} 1298$ & 0.92 \\
\hline 2 & Pouring point, ${ }^{\circ} \mathrm{C}$ & $\mathrm{D} 97$ & 5 \\
\hline 3 & Saponification value, $\mathrm{mg} \mathrm{KOH} / \mathrm{g}$ & $\mathrm{D} 464$ & 193 \\
\hline 4 & Acid number, $\mathrm{mgKOH} / \mathrm{g}$ & $\mathrm{D} 664$ & 124 \\
\hline 5 & Iodine number, $\mathrm{g} \mathrm{I} / \mathrm{l00g}$ & EN 1411 & 36.28 \\
\hline 6 & Water content, $\mathrm{mg} / \mathrm{kg}$ & D 95 & 670 \\
\hline 7 & Residue content, $\mathrm{mg} / \mathrm{kg}$ & EN 12622 & 452 \\
\hline
\end{tabular}

The special property of the deodorizer distillate was the very high value of free fatty acid with acid number of 124. Therefore that was impossible to convert this feedstock to biodiesel over the basic catalysts because of the saponification reactions [7]. The m-PSZ catalyst possessed superacid sites providing a very effective way to convert constantly esterification and trans-esterification of the free fatty acids and the triglycerides to biodiesel.

Beside, many other properties of the deodorizer distillate were the same trends as that of the vegetable oils or animal fats, so the applications of that kind of feedstock in the biodiesel synthesis were very suitable.

\subsection{Surveying the reaction parameters in the biodiesel synthesis}

Many parameters were surveyed in the biodiesel synthesis such as temperature, period of time, catalyst dosage, volume ratio of methanol/feedstock and stirring speed. The biodiesel synthesis process was gradually optimized through each survey by fixing the obtained parameter 
in the previous procedure and varying the rest parameters through each next reactions. The first parameter was temperature ranged from $80{ }^{\circ} \mathrm{C}, 100{ }^{\circ} \mathrm{C}, 120{ }^{\circ} \mathrm{C}, 130{ }^{\circ} \mathrm{C}$ and $140{ }^{\circ} \mathrm{C}$ during fixing the time of 3 hours, methanol/feedstock volume ratio of $1 / 1$, catalyst dosage of $4 \%$ and stirring speed of $400 \mathrm{rpm}$. The results were desribed in Tab. 3.

Table 3. Effect of temperature on biodiesel yield.

\begin{tabular}{|l|l|l|l|l|l|l|}
\hline Temperature, ${ }^{\circ} \mathrm{C}$ & 80 & 100 & 120 & $\mathbf{1 3 0}$ & 140 & 150 \\
\hline Biodiesel yield, \% & 70.4 & 82.3 & 89.6 & $\mathbf{9 2 . 2}$ & 90.0 & 86.2 \\
\hline
\end{tabular}

The best value of temperature was $130{ }^{\circ} \mathrm{C}$ when the biodiesel yield reached peak of $92.2 \%$. Below this temperature, the biodiesel yield was lower because of the lack of the kinetic energy [7]. At the temperature higher than $130{ }^{\circ} \mathrm{C}$, the biodiesel yield was also lower than that at $130{ }^{\circ} \mathrm{C}$. The reason was assigned for the byproduct generations or the increase of velocity of the inverse reactions instead of esterifications and transesterifications [8]. Therefore, the temperature of $130{ }^{\circ} \mathrm{C}$ was chosen for surveying the other parameters.

The second investigated parameter was the reaction time at $130{ }^{\circ} \mathrm{C}$. The fixed parameters includes methanol/feedstock volume ratio of $1 / 1$, catalyst dosage of $4 \%$ and stirring speed of $400 \mathrm{rpm}$. The reaction time was ranged from 1,2, 3, 4, 5 and 6 hours. The results were briefed in Table 4.

Table 4. Effect of reaction time on biodiesel yield.

\begin{tabular}{|l|l|l|l|l|l|l|}
\hline Reaction time, $h$ & 1 & 2 & 3 & $\mathbf{4}$ & 5 & 6 \\
\hline Biodiesel yield, \% & 73.2 & 85.8 & 92.2 & $\mathbf{9 4 . 5}$ & 94.6 & 94.6 \\
\hline
\end{tabular}

The reasonable phenomenon was that when raising the reaction time, the biodiesel yield also rised, but the biodiesel yield could not be risen by raising the reaction time to a very high value because of the kinetic limitations of the biodiesel synthesis. On the other hand, it could be said that the reaction gradually approached the balance state [8]. The biodiesel yield reached the highest value when the reaction time was 5 hours, but the yield at 4 hours was very the same. Therefore, the reaction time of 4 hours was chosen for further investigation of the effect of catalyst dosage on the biodiesel synthesis.

Table 5. Effect of catalyst dosage on biodiesel yield.

\begin{tabular}{|l|l|l|l|l|l|}
\hline Catalyst dosage, \% & 2 & 3 & 4 & $\mathbf{5}$ & 6 \\
\hline Biodiesel yield, \% & 80.1 & 90.1 & 94.5 & $\mathbf{9 5 . 5}$ & 95.5 \\
\hline
\end{tabular}

The m-PSZ catalyst dosages were varied from 2, 3, 4, 5 and $6 \%$ based on the feedstocks weight. The fixed conditions included tempereture of $130{ }^{\circ} \mathrm{C}$, reaction time of 4 hours, methanol/feedstock volume ratio of $1 / 1$ and stirring speed of $400 \mathrm{rpm}$. The results were shown up in Table 5.

The catalyst dosage also played a major effect on the biodiesel yield, and the principle was the same as the effect of the reaction time. In the former reaction, the catalyst dosage was $4 \%$ with the very high value of the biodiesel yield, but it could be applied with the higher weight (5\%) for enhancing the biodiesel synthesis. At this catalyst dosage, the biodiesel yield could reach $95.5 \%$. 
For the methanol/feedstock volume ratio investigations, some fixed conditions consisted of temperature of $130{ }^{\circ} \mathrm{C}$, reaction time of 4 hours, and catalyst dosage of $5 \% \mathrm{wt}$ and stirring speed of $400 \mathrm{rpm}$. The same survey was also implemented with the stirring speed when keeping the best methanol/feedstock volume ratio and changing the stirring speed from 100, 200, 300, 400, 500 and $600 \mathrm{rpm}$. The same behavior of the effects was observed, and finally we chose the most suitable methanol/feedstock volume ratio and stirring speed of $1.5 / 1$ and $500 \mathrm{rpm}$. The detail parameter investigations were described in Table 6 and Table 7.

Table 6. Effect of methanol/feedstock volume ratio on biodiesel yield.

\begin{tabular}{|l|l|l|l|l|l|l|}
\hline Methanol/feedstock volume ratio & $0.5 / 1$ & $1 / 1$ & $\mathbf{1 . 5 / 1}$ & $2 / 1$ & $2.5 / 1$ & $3 / 1$ \\
\hline Biodiesel yield, \% & 90.6 & 95.5 & $\mathbf{9 5 . 8}$ & 95.8 & 95.8 & 95.8 \\
\hline
\end{tabular}

Table 7. Effect of stirring speed on biodiesel yield

\begin{tabular}{|l|l|l|l|l|l|l|}
\hline Stirring speed, $r p m$ & 100 & 200 & 300 & 400 & $\mathbf{5 0 0}$ & 600 \\
\hline Biodiesel yield, \% & 87.6 & 92.2 & 94.0 & 95.8 & $\mathbf{9 6 . 3}$ & 96.3 \\
\hline
\end{tabular}

On the whole, the highest biodiesel yield coud be optimized to $96.3 \%$, a very high value demonstrating the extremely good catalysts activity, at conditions such as temperature of $130{ }^{\circ} \mathrm{C}$, reaction time of 4 hours, catalyst dosage of $5 \%$ wt, methanol/feedstock volume ratio of $1.5 / 1$ and stirring speed of $500 \mathrm{rpm}$.

\subsection{Determining the biodiesel composition and specifications}

Table 8. Chemical composition of the refined biodiesel.

\begin{tabular}{|l|l|l|l|}
\hline No. & Name & Simple formula & Content, \% \\
\hline 1 & Octanoic acid, methyl ester & $\mathrm{C} 8: 0$ & 0.09 \\
\hline 2 & Decanoic acid, methyl ester & $\mathrm{C} 10: 0$ & 0.14 \\
\hline 3 & Dodecanoic acid, methyl ester & $\mathrm{C} 12: 0$ & 0.88 \\
\hline 4 & Tetradecanoic acid, methyl ester & $\mathrm{C} 14: 0$ & 2.07 \\
\hline 5 & Pentadecanoic acid, methyl ester & $\mathrm{C} 15: 0$ & 0.13 \\
\hline 6 & Hexadecanoic acid, methyl ester & $\mathrm{C} 16: 0$ & 38.91 \\
\hline 7 & Heptadecanoic acid, methyl ester & $\mathrm{C} 17: 0$ & 0.49 \\
\hline 8 & 10,13-octadecadiennoic acid, methyl ester & $\mathrm{C} 18: 2$ & 33.55 \\
\hline 9 & 9-octadecenoic acid, methyl ester & $\mathrm{C} 18: 1$ & 11.28 \\
\hline 10 & Octadecanoic acid, methyl ester & $\mathrm{C} 18: 0$ & 6.19 \\
\hline 11 & $9,12-$ octadecadienoic acid, methyl ester & $\mathrm{C} 18: 2$ & 0.50 \\
\hline 12 & 11 -eicosenoic acid, methyl ester & $\mathrm{C} 20: 1$ & 0.63 \\
\hline 13 & Eicosanoic acid, methyl ester & $\mathrm{C} 20: 0$ & 0.97 \\
\hline Sum, $\%$ & & 97.83 \\
\hline
\end{tabular}


In this part, we have just analyzed the chemical composition of the refined biodiesel to estimate the adaptability of using it as a commercial product. Figure 3 showed the GC diagram of the refined biodiesel obtained from the synthesized process.

Table 8 described the chemical composition of the refined biodiesel when combining the GC peaks with the MS analysis results.

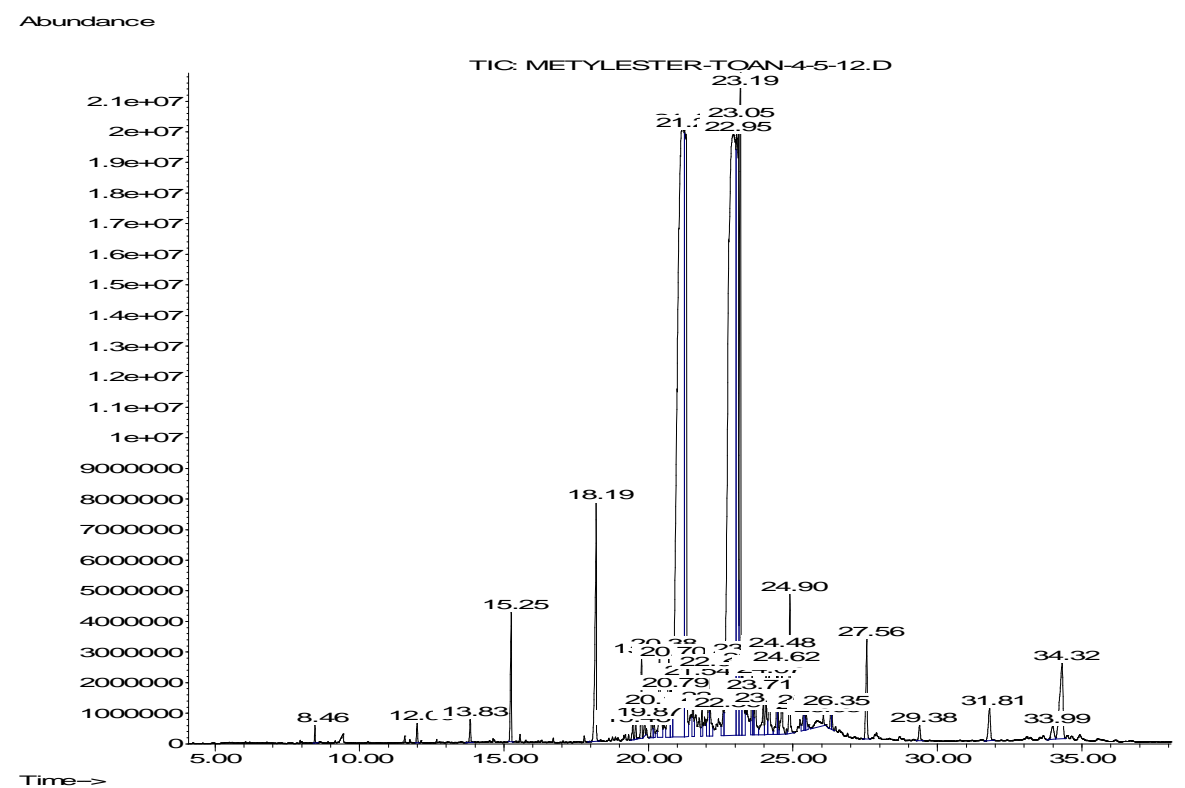

Figure 3. GC diagram of the refined biodiesel.

The total content of the methyl esters in the refined biodiesel reached $97.83 \%$ being higher than the required value according to the ASTM D 6751, so it had a high potential to use as commercial product. Some of the characteristics of the biodiesel were also described in Table 9.

Table 9. Some specifications of the synthesized biodiesel.

\begin{tabular}{|c|c|c|c|}
\hline Specifications & Methods & Values & ASTM D 6751 \\
\hline Density at $15.5^{\circ} \mathrm{C}$ & D 1298 & 0.8671 & - \\
\hline Flash point, ${ }^{\circ} \mathrm{C}$ & D 93 & 168 & $130 \mathrm{~min}$ \\
\hline Kinetic viscosity at $40{ }^{\circ} \mathrm{C}, \mathrm{cSt}$ & D 445 & 5.3 & $1.9-6.0$ \\
\hline Methyl ester content, wt\% & EN 14103d & 97.83 & 96.5 \\
\hline Cloud point, ${ }^{\circ} \mathrm{C}$ & D 2500 & 4 & - \\
\hline Cetane index & $\mathrm{J} 313$ & 56 & $47 \mathrm{~min}$ \\
\hline Acid value, $\mathrm{mg} \mathrm{KOH} / \mathrm{g}$ & D 664 & 0.30 & $0.50 \max$ \\
\hline Carbon residue, wt\% & D 4530 & 0.01 & $0.050 \max$ \\
\hline Sulphate ash, wt $\%$ & D 874 & 0.008 & $0.020 \max$ \\
\hline Water conten $\mathrm{t}, \mathrm{mg} / \mathrm{kg}$ & D 95 & 182 & $500 \max$ \\
\hline Alkali metal, $\mathrm{mg} / \mathrm{kg}$ & D 2896 & 4 & $5 \max$ \\
\hline Oxidative stability at $110^{\circ} \mathrm{C}$, hours & D 525 & 8 & $3 \mathrm{~min}$ \\
\hline
\end{tabular}


Most of the specifications were well adaptive with the proved ranges of the biodiesel for the commercial applications

\section{CONCLUSION}

The m-PSZ catalyst possessed high surface area, strong acidity, mesoporous structure. The catalyst could play an important role in many applications using superacid catalyst, ecspecilly in biodiesel synthesis from the rich free fatty acid feedstocks.

The biodiesel synthesis using vegetable oil deodorizer distillate over mesoporous oxophosphated sulfated zirconia (m-PSZ) showed a very high potential for appling this kind of catalyst in many other biodiesel production processes, ecspecially in the conversion of rich free fatty acid oils and fats. The refined biodiesel specifications met almost with the major specifications for biodiesel in commercial usage.

\section{REFERENCES}

1. Edgar Lotero, Yijun Liu, Dora E. Lopez, Kaewta Suwannakarn, David A. Bruce, and James G. Goodwin , Jr. - Synthesis of Biodiesel via Acid Catalysis, Ind. Eng. Chem. Res. 44 (14) (2005) 5353-5363.

2. Hoydonckx H.E., De Vos D.E., Chavan S.A., Jacobs P.A. - Esterification and transesterification of renewable chemicals, Top. Catal. 27(1-4) (2004) 83-96

3. Bondioli P. - The preparation of fatty acid esters by means of catalytic reactions, Top Catal. 27 (2004) 77-82.

4. Toda M., Takagaki A., Okamura M., Kondo J. N., Hayashi S., Domen K., Hara M. Green chemistry - Biodiesel made with sugar catalyst, Nature 438(7065) (2005) 178-178.

5. Anton A. Kiss, Alexandre C. Dimian, Gadi Rothenberg - Solid Acid Catalysts for Biodiesel Production - Towards Sustainable Energy, Advanced Synthesis \& Catalysis 348(1-2) (2006) 75-81.

6. Mbaraka, I.K., B.H. Shanks - Design of Multifunctionalized Mesoporous Silicas for Esterification of Fatty Acid, J. Catal. 229 (2005) 365-373.

7. Nguyen Khanh Dieu Hong, Pham Van phong, Dinh Thi Ngo - Preparation of solid superacid catalyst based on mesoporous sulfated zirconia, using for converting deodorizer distillate of vegetable oil to biodiesel, Tạp chí Hóa học 53(6E4) (2016) 72-79.

8. Nguyen Khanh Dieu Hong, Nguyen Dang Toan, Nguyen Trung Thanh, Nguyen Thi Ha Study on the relation between the conversion and product viscosity in the methanolysis of various feedstocks, International Symposium on Eco-materials Processing and Design 2014, ISBN 978-89-5708-236-2, Hanoi University of Science and Technology (2014) 154-158. 


\title{
TÓM TẮT
}

\section{NGHIÊN CƯUU CHUYỂN HÓA CẶN BÉO THẢI TỬ DẦU THỰC VẬT THÀNH BIODIESEL TRÊN XÚC TÁC ZICONI OXIT SUNFAT OXOPHOTPHAT HÓA}

\author{
Phạm Văn Phong ${ }^{1}$, Nguyễn Khánh Diệu Hồng ${ }^{2, * *}$ \\ ${ }^{I}$ Tập đoàn Dầu khí Quốc gia Việt Nam, 18 Láng Hạ, quận Ba Đình, Hà Nội \\ ${ }^{2}$ Đại học Bách khoa Hà Nội, số 1 Đại Cồ Việt, quận Hai Bà Trung, Hà Nội \\ "Email: dieuhong_bk@yahoo.com
}

Xúc tác ziconi oxit dạng mao quản trung bình sunfat oxophotphat hóa được sử dụng để chuyển hóa cặn béo thải từ dầu thực vật thành biodiesel trong phản ứng một giai đoạn. Xúc tác chứa hệ thống mao quản trung bình, có bề mặt riêng cao và sở hữu các tâm axit mạnh. Xúc tác vì thế có hiệu quả cao đối với cả các axit béo tự do và triglyxerit có trong thành phần cặn béo thải. Nghiên cứu này khảo sát bộ thông số công nghệ cho quá trình tổng hợp biodiesel trên, qua đó tìm ra các điều kiện thích hợp để thực hiện phản ứng.

Tù khóa: mao quản trung bình, ziconi oxit, oxophotphat hóa, cặn béo thải. 